\title{
Incidence of familial tendon dysfunction in patients with full-thickness rotator cuff tears
}

This article was published in the following Dove Press journal:

Open Access Journal of Sports Medicine

27 May 2014

Number of times this article has been viewed

\section{Robert Z Tashjian \\ Erik G Saltzman \\ Erin K Granger \\ Man Hung}

Department of Orthopedics, University of Utah Orthopaedic Center, University of Utah School of Medicine, Salt Lake City, UT, USA

Correspondence: Robert Z Tashjian Department of Orthopedics, University of Utah Orthopaedic Center, University of Utah School of Medicine, 590 Wakara Way, Salt Lake City, UT 84108, USA

$\mathrm{Tel}+\mathrm{I} 80$ I 5875457

Fax + I 80| 58754 |

Email robert.tashjian@hsc.utah.edu
Background: A familial predisposition to the development of rotator cuff tearing has been previously reported. Very little information exists on the development of global tendon dysfunction in patients with rotator cuff tears. The purpose of the current study was to determine the incidence of global tendon dysfunction as well as the need for surgery for tendon dysfunction in patients with rotator cuff tears and their family members and compare them to age-matched controls.

Methods: Ninety two patients with full-thickness rotator cuff tears and 92 age-matched controls with no history of shoulder dysfunction or surgery responded to several questions regarding tendon diseases in themselves as well as their family members. Individuals were queried regarding the presence of tendon diseases other than the rotator cuff, the need for surgery on these other tendinopathies, the presence of family members having tendinopathies including rotator cuff disease, and the need for family members to have surgery for these problems. Chi-square analysis was performed to compare the incidences between cases and controls $(P<0.05$ was considered significant).

Results: The average age of patients in the rotator cuff tear group and control groups were $58.24 \pm 7.4$ and $58.42 \pm 8.5$ years, respectively $(P=0.876$ ). Results showed $32.3 \%$ of patients in the rotator cuff tear group reported that family members had a history of rotator cuff problems or surgery compared to only $18.3 \%$ of the controls $(P=0.035)$, and $38.7 \%$ of patients in the rotator cuff tear group reported they had a history of other tendon problems compared to only $19.3 \%$ of individuals in the control group $(P=0.005)$.

Conclusion: Individuals with rotator cuff tears report a higher incidence of family members having rotator cuff problems or surgery as well as a higher incidence of other tendinopathies compared to controls. This data further supports a familial predilection for the development of rotator cuff tearing and generalized tendinopathies.

Keywords: family history, tendinopathies

\section{Introduction}

The etiology of rotator cuff disease is unknown but thought to be multifactorial. Possible etiologies of rotator cuff tendonitis or tearing include limited vascularity of the tendon, mechanical impingement on the undersurface of the acromion, and intrinsic degeneration. ${ }^{1-3}$ The natural history data on rotator cuff disease supports a familial component. ${ }^{4}$ Sibling data exist regarding the presence of rotator cuff disease which suggest a familial pattern and therefore potentially a genetic influence. ${ }^{5}$ Finally, there is emerging evidence that suggests other tendinopathies have genetic origins including possible abnormalities of the collagen $5 \mathrm{Al}$ (COL5A1) gene or tenascin C (TNC) gene, both localized to chromosome $9 .{ }^{6-8}$ Consequently, there may be a predisposition 
for patients with one type of tendinopathy to develop a subsequent tendinopathy, as well as have family members at an increased risk for developing tendinopathies.

When specifically looking at rotator cuff tendon injuries, several studies suggest a genetic influence on development of the disease. Yamaguchi et al evaluated 586 patients who had a diagnostic shoulder ultrasound for shoulder pain and found a strong trend of reported family history of rotator cuff tearing in individuals with a rotator cuff tear compared to those without a tear $(10.9 \%$ versus $6.9 \%, P=0.06) .{ }^{4}$ Harvie et al retrospectively evaluated the 129 siblings of a cohort of 205 patients diagnosed with full-thickness rotator cuff tears by ultrasound to identify the prevalence of rotator cuff tearing in this sibling population. ${ }^{5}$ They determined that siblings of patients with full-thickness rotator cuff tears had an increased relative risk for tearing compared to controls. These same authors reevaluated the same cohort of siblings and controls 5 years later for progression of tearing. ${ }^{9}$ The authors determined that the relative risk of full-thickness tears in siblings compared to controls was significantly greater 5 years after the initial evaluation. Similarly, tear enlargement occurred 16\% of the time in siblings and only $1.5 \%$ of the time in controls over the 5-year period. Finally, previously published results support a genetic predisposition for individuals with rotator cuff disease utilizing a large population database. ${ }^{10}$ This study suggests familial and genetic factors likely have a role in the development and the progression of rotator cuff disease and tearing. No prior studies have evaluated the coexistence of various tendinopathies within the same individual and the coexistence of various tendon diseases within family members of patients with tendinopathies.

The purpose of this study was to determine the incidence of various tendinopathies and a family history of tendinopathies in a group of patients with full-thickness rotator cuff tears and compare these rates to age-matched controls. Our hypothesis was that patients with full-thickness rotator cuff tears will have a higher reported incidence of other treated tendinopathies and family members with tendinopathies than age-matched controls. Evidence from this study could further strengthen the argument of a familial and genetic predisposition for the development of rotator cuff tearing and generalized tendinopathies.

\section{Materials and methods}

A cohort of patients with magnetic resonance imaging (MRI)-confirmed, symptomatic, full-thickness rotator cuff tears were recruited into this study as part of a larger study evaluating the genetic predisposition for rotator cuff tearing. Each patient with a rotator cuff tear was recruited out of the primary surgeon's clinic (RZT), and all had a full-thickness rotator cuff tear confirmed by MRI. Prior to initiating recruitment, the study was approved by the University of Utah investigational review board. All patients subsequently completed a written questionnaire regarding information on their medical, social, and family history. Information obtained included data regarding the presence of other tendinopathies, the occurrence of surgical procedures for other tendinopathies, the presence of a family history of rotator cuff disease and other tendinopathies in general, and the occurrence of surgical treatment of these tendon problems in family members. All patients completed a shoulder functional outcome questionnaire including the Simple Shoulder Test (SST). ${ }^{11}$ A total of 179 patients were recruited into the rotator cuff tear group.

A separate cohort of individuals was recruited as population-based controls to compare against the cohort of patients with documented full-thickness rotator cuff tears. Individuals were recruited in the waiting areas of three different clinics at the University of Utah. All of the clinics where control cohort individuals were recruited had no relation to the treatment of musculoskeletal diseases. Inclusion criteria were any individual over the age of 18 with no shoulder pain and no prior shoulder injury or surgery. Study participants completed the same questionnaire evaluations as the patients with full-thickness rotator cuff tears. The control cohort also completed the SST. A total of 122 individuals were recruited into the control group.

Since age is known to have a strong correlation with the development of symptomatic and asymptomatic rotator cuff tears, a matched subset of these two groups was used to perform the analysis. Matching was based on age to within 5 years. The final sample consisted of 93 patients with rotator cuff tears and 93 age-matched population controls.

\section{Statistical analysis}

Student's $t$-test was performed to compare ages and SST scores between the rotator cuff tear and control groups. Chi-square analysis was performed to compare the number of "yes" and "no" answers to the following questions between the rotator cuff tear and control groups: 1) "Do any of your family members have a history of rotator cuff problems or surgery?"; 2) "Do any of your family members have a history of tendon problems or surgery?"; 3) "Do you have a history of any other tendon problems?"; 4) "Have you had any other prior tendon surgeries?" The significance level was set at $P<0.05$. 


\section{Results}

The average age of patients in the rotator cuff tear group and control groups was $58.24 \pm 7.4$ and $58.42 \pm 8.5$ years, respectively $(P=0.876)$. There was a normal distribution of individuals between age groups (groupings every 5 years) from ages 40 to 75 (Figure 1). As seen in Figure 2, there were 72 males and 21 females in the rotator cuff tear group and 55 females and 38 males in the control group. Since there is evidence supporting an increased incidence of tearing based upon sex, matching was performed based upon age. The average SST score of the rotator cuff tear group was significantly lower than that of the control group $(4.5 \pm 3.5$ versus $10.9 \pm 2.1, P<0.001)$.

When asked "Do any of your family members have a history of rotator cuff problems or surgery?", $32.3 \%$ of patients in the rotator cuff tear group answered yes, while only $18.3 \%$ of individuals in the control group answered yes $(P=0.035)$. When asked "Do any of your family members have a history of tendon problems or surgery?", $22.8 \%$ of patients in the rotator cuff tear group answered yes, while only $17.5 \%$ of individuals in the control group answered yes $(P=0.407)$. When asked "Do you have a history of any other tendon problems?", $38.7 \%$ of patients in the rotator cuff tear group answered yes, while only $19.3 \%$ of individuals in the control group answered yes $(P=0.005)$. Finally, when asked "Have you had any other prior tendon surgeries?", $18.3 \%$ of patients in the rotator cuff tear group answered yes, while

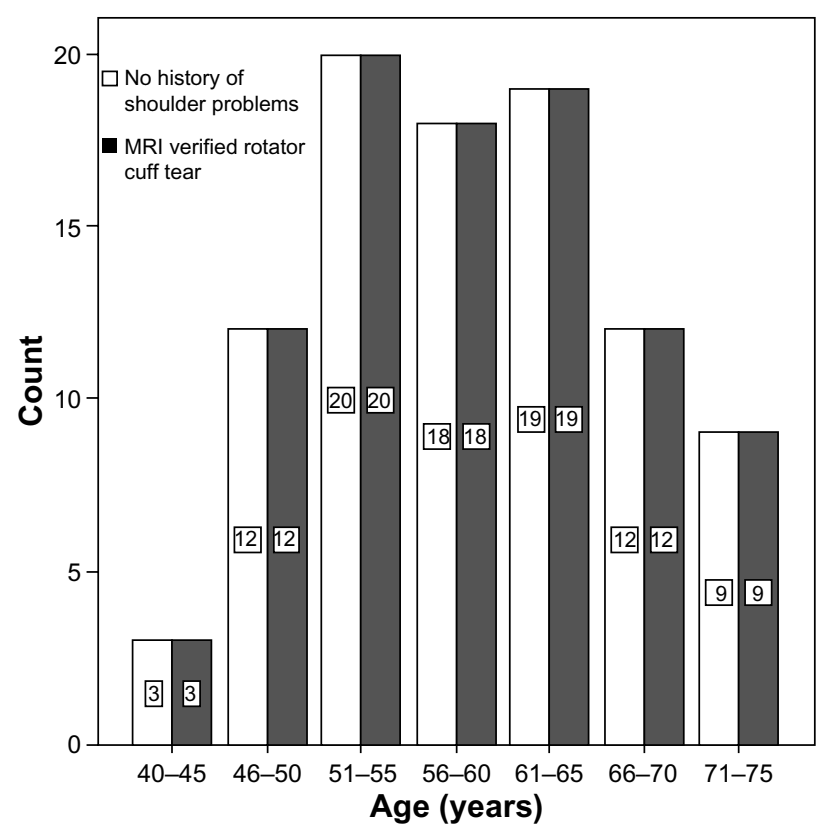

Figure I Age distribution of rotator cuff tear group (grey) and control group (white).

Abbreviation: MRI, magnetic resonance imaging.

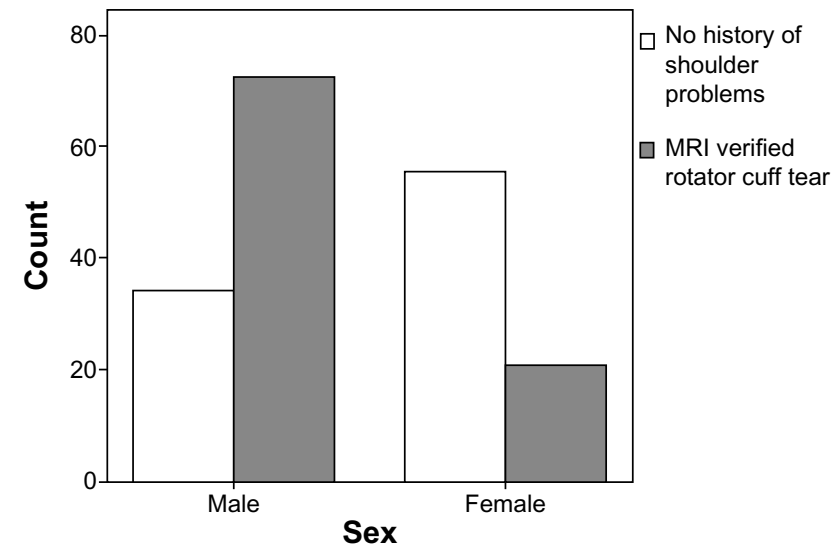

Figure 2 Sex distribution of rotator cuff tear group (grey) and control group (white).

Abbreviation: MRI, magnetic resonance imaging.

only $13.6 \%$ of individuals in the control group answered yes $(P=0.605)$.

\section{Discussion}

A familial predisposition to rotator cuff tearing has been previously identified. Very little information exists regarding the association of rotator cuff tearing and the presence and treatment of other tendinopathies. In this study, patients with full-thickness rotator cuff tears reported statistically significant higher rates of family members having rotator cuff problems and higher rates of other tendon problems compared to age-match population controls. Patients with full-thickness rotator cuff tears reported higher rates of family members with various tendon problems and higher rates of having other prior tendon surgeries compared to controls, although the differences were not statistically significant. This data further supports that there is a familial component to rotator cuff tearing. Furthermore, individuals with a single tendon problem (rotator cuff tearing) are more likely to develop another tendon problem.

The findings from this study support a potential genetic predisposition for rotator cuff tearing and the development of tendinopathies. Previously published research demonstrates a potential genetic predisposition for rotator cuff tearing using the Utah Population Data Base. ${ }^{10}$ Tashjian et a ${ }^{10}$ identified individuals treated for rotator cuff disease who also had at least three generations of genealogy data. A high-risk population for a genetic contribution was identified (young patients under the age of $40 ; n=652$ ), with significantly elevated risk of developing rotator cuff disease in family members of individuals with rotator cuff disease (cases) compared to individuals without rotator cuff disease (controls) out to third-degree relatives (relative risk $=1.81, P=0.0479$ ). The 
observation of significantly elevated risk to distant relatives of cases strongly supports a heritable predisposition to rotator cuff disease. The current data further support a familial component to the etiology of rotator cuff tearing.

Very limited data exist regarding the association between various tendinopathies. The largest body of data evaluating the genetic link between tendinopathies is reported for patients with Achilles tendinopathy or tearing. Several studies have reported a correlation between blood groups $\mathrm{O}$ or the $\mathrm{A} / \mathrm{O}$ ratio and Achilles tendon ruptures. ${ }^{12-14}$ Recently, the ABO gene has been considered a potential marker for other genes colocalized to the same region of chromosome 9 . Two genes have been localized to the same region on chromosome 9 as the $A B O$ gene; $T N C$, and $C O L 5 A 1$, which have been shown to have polymorphisms associated with presence of Achilles tendon injuries. ${ }^{6,7}$ TNC is a glycoprotein found in tendons whose expression is regulated in a dose-response manner by mechanical loading in tendons. The protein binds to various cell surface receptors including integrins and has been implicated in the regulation of cell-matrix interactions. TNC expression has been shown in Achilles tendinopathy. The COL5A1 gene encodes the alpha 1 chain of type $\mathrm{V}$ fibrillar collagen. Type $\mathrm{V}$ collagen is found in tendons and other connective tissues, where it regulates the assembly of collagen fibers. Variants in either of these genes are ideal candidate genes for Achilles tendon injuries and potentially other tendinopathies, including rotator cuff disease. The current study further supports an association between tendinopathies in affected individuals. Data from this study can be utilized to counsel patients regarding an increased risk for development of associated tendinopathies in the presence of rotator cuff tearing. Preventative strategies may be employed, including modification of work and recreational activities to limit overuse.

There are several limitations of the current study. First, the study relied on a questionnaire. We did not specifically query each family member, consequently the information is based only upon what each study participant knows of their family's medical history. There may be bias for individuals who know more about their family's medical history regarding members having been affected with a similar disease. Second, the control group was age-matched, without knowledge of the group's underlying rotator cuff tendon status. We specifically age-matched since there is good evidence to support that age-related asymptomatic rotator cuff tearing occurs. ${ }^{3}$ We likely included some individuals in the control group who had asymptomatic rotator cuff tears based upon this data. Nevertheless, we still see statistically significant differences in the reporting of other associated tendinopathies in the controls versus rotator cuff group as well as reporting of family members having a history of tendinopathies. If we did perform a study to confirm the lack of rotator cuff disease in the control group, the differences would likely be larger. Finally, it is unclear if the family members who patients are reporting are first degree, second degree, or beyond. Closer relatives have a higher chance of environmental effects leading to an increased incidence of similarly reported diseases, whereas more remote relatives are more likely to be affected by genetic effects.

\section{Conclusion}

Patients with rotator cuff tears report higher rates of associated tendinopathies or family members with tendinopathies than age-matched controls. This data further supports a familial predisposition for rotator cuff tearing and the development of tendinopathies in general. Further research is warranted to identify genes or genetic variants associated with rotator cuff tearing or tendinopathies, as this information will be helpful to identify individuals at-risk and potentially direct future biologic treatment options for tendinopathies.

\section{Disclosure}

The authors report no conflicts of interest in this work.

\section{References}

1. Blevins F, Djurasovic M, Flatow E, Vogel K. Biology of the rotator cuff. Orthop Clin North Am. 1997;28:1-15.

2. Neer CS. Anterior acromioplasty for the chronic impingement syndrome in the shoulder: a preliminary report. J Bone Joint Surg Am. 1972;54(1):41-50.

3. Sher JS, Uribe JW, Posada A, Murphy BJ, Zlatkin MB. Abnormal findings on magnetic resonance images of asymptomatic shoulders. J Bone Joint Surg Am. 1995;77(1):10-15.

4. Yamaguchi K, Baumgarten K, Gerlach DJ, et al. The demographics and morphology of rotator cuff disease: a comparison of asymptomatic and symptomatic shoulders. Paper presented at: 9th International Congress on Surgery of the Shoulder; May 2-4, 2004; Washington, DC. Paper 52B.

5. Harvie P, Ostlere SJ, Teh J, et al. Genetic influences in the aetiology of tears of the rotator cuff. Sibling risk of a full-thickness tear. J Bone Joint Surg Br. 2004;86(5):696-700.

6. Mokone GG, Schwellnus MP, Noakes TD, Collins M. The COL5A1 gene and Achilles tendon pathology. Scand J Med Sci Sports. 2006;16(1): 19-26.

7. Mokone GG, Gajjar M, September AV, et al. The guanine-thymine dinucleotide repeat polymorphism within the tenascin- $C$ gene is associated with achilles tendon injuries. Am J Sports Med. 2005;33(7): 1016-1021.

8. September AV, Schwellnus MP, Collins M. Tendon and ligament injuries: the genetic component. Br J Sports Med. 2007;41(4):241-246; discussion 246.

9. Gwilym SE, Watkins B, Cooper CD, et al. Genetic influences in the progression of tears of the rotator cuff. J Bone Joint Surg Br. 2009;91(7): 915-917. 
10. Tashjian RZ, Farnham JM,AlbrightFS, Teerlink CC, Cannon-AlbrightLA. Evidence for an inherited predisposition contributing to the risk for rotator cuff disease. J Bone Joint Surg Am. 2009;91(5):1136-1142.

11. Lippitt SB, Harryman DT, Matsen FA. A practical tool for evaluating function: the Simple Shoulder Test. In: Matsen FA, Fu FH, Hawkins RJ, editors. The Shoulder: a balance of mobility and stability. Rosemont, IL: American Academy of Orthopedic Surgeons; 1993:501-518.
12. Kannus P, Natri A. Etiology and pathophysiology of tendon ruptures in sports. Scand J Med Sci Sports. 1997;7(2):107-112.

13. Jozsa L, Balint JB, Kannus P, Reffy A, Barzo M. Distribution of blood groups in patients with tendon rupture. An analysis of 832 cases. $J$ Bone Joint Surg Br. 1989;71(2):272-274.

14. Kujala UM, Järvinen $\mathrm{M}$, Natri $\mathrm{A}$, et al. ABO blood groups and musculoskeletal injuries. Injury. 1992;23(2):131-133.

Open Access Journal of Sports Medicine

\section{Publish your work in this journal}

Open Access Journal of Sports Medicine is an international, peer-reviewed, open access journal publishing original research, reports, reviews and commentaries on all areas of sports medicine. The manuscript management system is completely online and includes a very quick and fair peer-review system.
Visit http://www.dovepress
from published authors.

Visit http://www.dovepress.com/testimonials.php to read real quotes (1) 